\title{
Biological effective dose evaluation and assessment of rectal and bladder complications for cervical cancer treated with radiotherapy and surgery
}

\author{
Catharina Beskow, PhD ${ }^{12}$, Anna-Karin Ågren-Cronqvist, PhD³, Rolf Lewensohn, PhD4, Iuliana Toma-Dasu, PhD \\ 'Department of Oncology and Pathology, Karolinska Institutet, 2Department of Gynecologic Oncology, Radiumhemmet, Karolinska University \\ Hospital, ${ }^{3}$ Department of Medical Physics, Karolinska University Hospital, ${ }^{4}$ Karolinska Biomics Center, Department of Oncology and Pathology, \\ Karolinska Institutet, ${ }^{5}$ Medical Radiation Physics, Stockholm University
}

\begin{abstract}
Purpose: This study aims to retrospectively evaluate dosimetric parameters calculated as biological effective dose in relation to outcome in patients with cervical cancer treated with various treatment approaches, including radiotherapy with and without surgery.

Material and methods: Calculations of biological effective dose (BED) were performed on data from a retrospective analysis of 171 patients with cervical carcinoma stages IB-IIB treated with curative intent, between January 1989 and December 1991. 43 patients were treated only with radiotherapy and 128 patients were treated with a combination of radiotherapy and surgery. External beam radiotherapy was delivered with 6-21 MV photons from linear accelerators. Brachytherapy was delivered either with a manual radium technique or with a remote afterloading technique. The treatment outcome was evaluated at 5 years.

Results: The disease-specific survival rate was $87 \%$ for stage IB, $75 \%$ for stage IIA and $54 \%$ for stage IIB, while the overall survival rates were $84 \%$ for stage IB, $68 \%$ for stage IIA and $43 \%$ for stage IIB. Patients treated only with radiotherapy had a local control rate of $77 \%$ which was comparable to that for radiotherapy and surgery patients (78\%). Late complications were recorded in 25 patients (15\%). Among patients treated with radiotherapy and surgery, differences in radiation dose calculated as $\mathrm{BED}_{10}$ did not seem to influence survival. For patients treated with radiotherapy only, a higher $\mathrm{BED}_{10}$ was correlated to a higher overall survival $(p=0.0075)$. The dose response parameters found based on biological effective dose calculations were $\mathrm{D}_{50}=85.2 \mathrm{~Gy}_{10}$ and the normalized to total dose slope of the dose response curve $\gamma=1.62$ for survival and $\mathrm{D}_{50}=61.6 \mathrm{~Gy}_{10}$ and $\gamma=0.92$, respectively for local control.

Conclusions: The outcome correlates with biological effective dose for patients treated with radiation therapy alone, but not for patients treated with radiotherapy and surgery. No correlations were found between BED and late toxicity from bladder and rectum.

Key words: BED, bladder complication, cervical cancer, radiotherapy and surgery, rectal complication.

\section{Purpose}

Radiotherapy (RT) is a well established method for treatment of cervical cancer. Definitive RT includes external beam radiation therapy (EBRT) to the pelvis and intracavitary brachytherapy (BT). RT in combination with surgery has been used for treatment of local disease, where RT has been added postoperatively to cases, showing unfavorable prognostic feature at surgery or has been given preoperatively [1-4]. Comparisons between treatment regimens with different fractionations, dose rates and treatment time as well as the evaluation of their effectiveness on tumor and normal tissues is possible through the use of bioeffect dose models that take into account the variation of the response with all the above-mentioned factors. The linear quadratic (LQ) model is currently the most used model for this purpose as it can account for differences in time, dose and fractionation with a relatively small number of parameters [5-7]. Several studies have investigated the predictive value of the LQ model in treatment of cervical cancer using BT [9-11], but there are very few reports on biological effective dose 
(BED) and the outcome of the patients treated with a combination of radiotherapy and surgery. One recent study on cervical cancer patients treated with MRI-guided preoperative brachytherapy has investigated dose volume histogram parameters and outcome [13]. However, to the best of our knowledge, there is no study investigating the relationship between the biological effective dose (BED) and the outcome of patients treated with a combination of radiotherapy and surgery.

It is therefore the aim of this paper to explore the relationship between BED for various treatment schedules and local control, overall survival and the risk for bladder and rectal complications for patients treated with RT combined with surgery or RT alone.

\section{Material and methods}

\section{Patients}

A retrospective study was performed on 171 patients with cervical carcinoma FIGO stage IB-IIB treated with curative intent using RT combined with surgery or RT alone, between January 1989 and December 1991. One-hundred-andthirteen patients were diagnosed in stage IB, 44 patients in stage IIA and 14 cases in stage IIB. Squamous cell carcinoma was diagnosed in 126 patients and adenocarcinoma in 34 cases (Table 1 ). Age at diagnosis varied between 22 and 87 years with a median of 43 years for patients treated with combination RT and surgery and 72 years for patients treated with RT only. Median follow up was 66 months (range 8-109 months). Outcome, in terms of survival and local con-

Table 1. Patient characteristics

\begin{tabular}{|c|c|c|}
\hline \multirow[t]{2}{*}{ Characteristic } & \multicolumn{2}{|c|}{ Number } \\
\hline & of patients & $\%$ \\
\hline Total & 171 & \\
\hline \multicolumn{3}{|l|}{ Stage } \\
\hline $\mathrm{IB}$ & 113 & 66 \\
\hline$\| A$ & 44 & 26 \\
\hline IIB & 14 & 8 \\
\hline \multicolumn{3}{|l|}{ Histologic type } \\
\hline Squamous cell carcinoma & 126 & 74 \\
\hline Adenocarcinoma & 34 & 20 \\
\hline Others & 11 & 6 \\
\hline \multicolumn{3}{|l|}{ Treatment } \\
\hline BT + surgery & 97 & 57 \\
\hline $\mathrm{BT}+$ surgery + EBRT & 31 & 18 \\
\hline $\mathrm{BT}+\mathrm{EBRT}$ & 43 & 25 \\
\hline \multicolumn{3}{|l|}{ BT } \\
\hline Manual & 91 & 53 \\
\hline After-loading & 80 & 47 \\
\hline \multicolumn{3}{|l|}{ EBRT } \\
\hline Pelvic alone & 49 & 66 \\
\hline Pelvic + para-aortic & 25 & 34 \\
\hline
\end{tabular}

$B T$ - brachytherapy, EBRT - external beam radiotherapy trol, were defined at five years. Late side effects were recorded until death or lost of follow-up. Late complications in bladder and rectum were recorded retrospectively according to the glossary of Chassagne [14] and were defined as complications persistent or occurring more than three months after radiotherapy. Complications grade 2 included symptoms resulting in intermittent or persistent interference with normal activity and/or requiring investigation such as rectoscopy or cystoscopy; grade 3 complications were defined as symptoms that affect the performance status of the patient and that require surgery or invasive procedures.

\section{Treatment}

During the period of this study, the treatment of choice at the Department of Gynecologic Oncology, Radiumhemmet, Karolinska University Hospital, for patients with cervical cancer stage IB and IIA was intracervical preoperative brachytherapy. If lymph node metastases or unradical resection margins were diagnosed at surgery, postoperative external beam radiotherapy (EBRT) was added. Patients in stage IIB were treated with radiotherapy (RT) alone, as well as patients in stage IB and IIA not suitable for surgery due to medical reasons. For 128 patients, treatment included two BT fractions with a three-week interval, followed by radical surgery according to the WertheimMeig procedure four weeks after the second BT. Postoperative EBRT over a pelvic and a para-aortic field was added to cases with lymph node metastases, while patients with non-radical surgery received EBRT over the pelvis. Fortythree patients were treated with radiotherapy only, including two BT fractions with a three week interval, followed by EBRT over the pelvis four weeks later (Table 1). EBRT was delivered by 6-21 MV linear accelerators using A-P fields with a daily fractionation of $1.6 \mathrm{~Gy}$. The prescribed dose to the pelvis was $45 \mathrm{~Gy}$ (median 44.2 Gy; range 40-50 Gy) and to the para-aortic field $40 \mathrm{~Gy}$ (median $40 \mathrm{~Gy}$; range 10.6-45.6 Gy). Central shielding was performed from the start of EBRT with an individualized shielding to the bladder and rectum depending on the dose already given by BT, and the dose to the organs at risk under the shielding was determined based on the computerized treatment planning system.

All patients received low dose rate brachytherapy. However, during the studied period, brachytherapy technique changed from manual radium technique to remote after-loading technique with cesium-137 (Selectron $\left.{ }^{\circledR}\right)$. The manual technique was used in 39 cases (91\%) in the group of patients treated by RT only and in 52 cases $(41 \%)$ among patients treated by RT and surgery. In manual technique, the dose to bladder and rectum was estimated by measuring the dose rate by a gammameter at multiple points and the clinical dose to point $A$ was retrospectively estimated to a median of $56 \mathrm{~Gy}$ (range 22-66 Gy). In the after-loading technique the rectal point dose was calculated at the anterior rectal wall five $\mathrm{mm}$ below the posterior level of the ringapplicator and the dose to bladder was estimated at a point on the posterior surface of a catheter balloon according to the International Commission on Radiation Units and Measurements Report 38 recommendations [15]. The median dose to point A was $45 \mathrm{~Gy}$ (range 28-52 Gy). A detailed 
description of the two BT techniques used has been reported elsewhere [16].

\section{Bioeffect dose calculations}

Comparison between the various treatment techniques was done based on biologically effective dose (BED) [6,7], which allows easy comparison and addition of the effects of various complete or partial treatment regimens, irrespective of method or pattern of delivery employed.

For EBRT, BED could be calculated according to equation 1.

$$
B E D_{E B R T}=n d\left\{1+\frac{d}{\alpha / \beta}\right\}
$$

where $n$ is the number of fractions, $d$ is the dose per fraction and $\alpha / \beta$ is the ratio of the LQ parameters of the tissue investigated. When central shielding was used with an individualized shielding to the bladder and rectum, the dose to organs at risk determined under the shielding was used in the above formula for calculating the corresponding biologically effective dose.

For low dose rate BT where significant repair of damage takes place during the treatment duration, BED for each session is given by equation 2 .

$$
B E D_{B T}=D\left\{1+\frac{2 D}{(\alpha / \beta) \mu T}\left[1-\frac{1}{\mu T}\left(1-e^{-\mu T}\right)\right]\right\}
$$

where $D$ is the radiation dose, $T$ is the duration of the BT session and $\mu$ is a parameter characterizing the repair of sublethal damage in the irradiated tissues; $\mu=\ln (2) / T_{1 / 2}$ where $\mathrm{T}_{1 / 2}$ is half-life of sublethal damage repair.

For combined treatment schedules, one could calculate the total BED as:

$$
B E D_{\text {tot }}=\sum_{i} B E D_{i}
$$

where $B E D_{i}$ are individual biologically effective doses from each session of RT.

Equation 3 gives the general BED expression that does not take into account the proliferation during treatment. However, tumor cell kinetic studies showed that proliferation of the cells after the start of treatment could be significantly higher than the proliferation before the initiation of irradiation, and therefore the biologically effective dose to the tumor could decrease to as much as about $1 \mathrm{~Gy} /$ day [8]. The effect of proliferation could be expressed through a supplementary term subtracted from $\mathrm{BED}_{\text {tot }}$ (equation 4 ).

$B E D_{\text {prolif }}=\sum_{i} B E D_{i}-\frac{\ln (2)}{\alpha} \frac{T_{\text {treat }}-T_{k}}{T_{p}}$

where $T_{\text {treat }}$ is the overall treatment time, $T_{k}$ is the time for the onset of proliferation [17], $T_{p}$ is the effective doubling time during proliferation and $\alpha$ is the linear parameter of LQ model. Thus, the repopulation time $T_{p}$ describes the proliferation of tumors after damage has been inflicted through treatment. It is thought to describe the proliferation without inhibiting factors such as nutrient supply or even as the result of active processes as appear in the healing of normal tissues. The actual time available for accelerated repopulation is $T_{\text {treat }}-T_{k}$ and therefore no correction for proliferation is needed if the overall treatment time is shorter than $T_{k}$.

The expressions in equations 1-4 were used to calculate BED for tumors and normal tissues. The parameters used for calculations have been chosen in agreement with existing literature [8,12,17]. Generic values of $10 \mathrm{~Gy}$ and $3 \mathrm{~Gy}$ have been assumed for the fractionation sensitivities of tumors and normal tissues, respectively. The corresponding biologically effective dose for tumor was denoted $\mathrm{BED}_{10}$ and for the organs at risk $\mathrm{BED}_{3}$, respectively. The repair halflife for sublethal damage was $1.5 \mathrm{~h}$ resulting in a repair parameter $\mu=0.46 \mathrm{~h}^{-1}$, the time for the onset of proliferation $T_{k}=21$ days, the effective proliferation doubling time $T_{p}=5$ days and $\alpha=0.3 \mathrm{~Gy}^{-1}$

The biological effective dose is further reported as BED calculated as described the above section, but also as equivalent dose in $2 \mathrm{~Gy}$ per fraction, $\mathrm{EQD}_{2}$, calculated as:

$$
E Q D_{2}=\frac{B E D}{1+\frac{2}{\alpha / \beta}}
$$

In this way the comparison of the results with previously reported studies using the BED concept could be easily performed, but also further comparison with studies following the new recommendations of the European Gynecological Brachytherapy Group/European Society of Therapeutic Radiology and Oncology (GEC-ESTRO) for dose reporting [19], which recommends the use of the $\mathrm{EQD}_{2}$-formalism.

\section{Results}

\section{Tumor response}

The disease-specific 5-year survival rate (DSS) was $87 \%$ for stage IB, $75 \%$ for stage IIA and $54 \%$ for stage IIB. The corresponding overall 5-year survival rates (OAS) were $84 \%$, $68 \%$ and $43 \%$, respectively. Patients treated with radiotherapy and surgery had a local control rate at five years of $78 \%$, while for patients treated with RT alone the fiveyear local control rate was $77 \%$. Table 2 presents a summary of the overall survival data for all the patients in the study divided according to stage of disease and treatment type, together with the mean and median $\mathrm{BED}_{10}$ without considering proliferation for each group. The data in the table shows that for the group of patients treated only with radiation therapy, the outcome appears to correlate with radiation dose. For the group of patients treated with BT and surgery, differences in irradiation dose calculated as $\mathrm{BED}_{10}$ did not seem to influence overall survival. Among patients receiving a combination of both BT and EBRT together with surgery, the results diverge with an inverted correlation between $\mathrm{BED}_{10}$ and survival for patients in stage $\mathrm{IB}$, suggesting 
Table 2. Summary of the patient data on overall survival and BED to the tumour for the stage Ib, Ila and IIb patients treated with radiotherapy and surgery or with radiotherapy alone

\begin{tabular}{|c|c|c|c|}
\hline & \multicolumn{3}{|c|}{ Treatment type } \\
\hline & Brachy + Surgery & Brachy + Surgery + EBRT & Brachy + EBRT \\
\hline Total no. of patients & 97 & 31 & 43 \\
\hline \multicolumn{4}{|l|}{ Stage lb } \\
\hline No. of patients & 82 & 14 & 17 \\
\hline Mean $\mathrm{BED}_{10}\left(\mathrm{~Gy}_{10}\right)$ & 71 & 101 & 100 \\
\hline Median $B D_{10}\left(G_{10}\right)$ & 68 & 103 & 104 \\
\hline Surviving fraction of patients with $\mathrm{BED}_{10}<$ Median $\mathrm{BED}_{10}$ & $93 \%$ & $43 \%$ & $63 \%$ \\
\hline Surviving fraction of patients with $\mathrm{BED}_{10}>$ Median $\mathrm{BED}_{10}$ & $90 \%$ & $29 \%$ & $89 \%$ \\
\hline \multicolumn{4}{|l|}{ Stage lla } \\
\hline No. of patients & 13 & 14 & 17 \\
\hline Mean $\mathrm{BED}_{10}\left(\mathrm{~Gy}_{10}\right)$ & 73 & 102 & 96 \\
\hline Median BED $10\left(\mathrm{~Gy}_{10}\right)$ & 76 & 105 & 97 \\
\hline Surviving fraction of patients with $\mathrm{BED}_{10}<$ Median $\mathrm{BED}_{10}$ & $100 \%$ & $29 \%$ & $44 \%$ \\
\hline Surviving fraction of patients with $\mathrm{BED}_{10}>$ Median $\mathrm{BED}_{10}$ & $100 \%$ & $57 \%$ & $78 \%$ \\
\hline \multicolumn{4}{|l|}{ Stage IIb } \\
\hline No. of patients & 2 & 3 & 9 \\
\hline Mean $\mathrm{BED}_{10}\left(\mathrm{~Gy}_{10}\right)$ & 84 & 81 & 72 \\
\hline Median $B D_{10}\left(G_{10}\right)$ & 84 & 88 & 79 \\
\hline Surviving fraction of patients with $\mathrm{BED}_{10}<$ Median $\mathrm{BED}_{10}$ & $100 \%$ & $0 \%$ & $20 \%$ \\
\hline Surviving fraction of patients with $\mathrm{BED}_{10}>$ Median $\mathrm{BED}_{10}$ & $0 \%$ & $50 \%$ & $60 \%$ \\
\hline
\end{tabular}

more complicated pattern of correlations. The remaining analysis will therefore focus on the group of patients receiving only RT.

Figure 1 shows the distribution of patients treated with $\mathrm{RT}$ only, according to $\mathrm{BED}_{10}$ and their overall survival status at the follow-up time. The data show that the surviving patients had higher mean and median $\mathrm{BED}_{10}$ than the patients that were deceased at the time of analysis. This indicates a positive correlation between $\mathrm{BED}_{10}$ and treatment outcome for the patients receiving only RT. This is illustrated in Fig. 2 where $\mathrm{BED}_{10}$ above the median value of $94 \mathrm{~Gy}_{10}$, corresponding to an equivalent dose in 2 Gy per fraction $\left(\mathrm{EQD}_{2}\right)$ of $81 \mathrm{~Gy}$, correlates with better overall survival $(p=0.0075)$. The same tendency is maintained if proliferation is taken into account for $\mathrm{BED}_{10}$ calculation.

The dose dependence of overall survival for the 43 patients treated with RT alone is represented in Fig. 3. A logit fit of the data yields a D50 of $85.2 \mathrm{~Gy}_{10}$, the mean biological effective dose to the tumor that corresponds to a surviving fraction of $50 \%$ of the patients, corresponding to an $\mathrm{EQD}_{2}$ of $71 \mathrm{~Gy}$. The gamma slope was 1.62. A similar analysis was performed with $\mathrm{BED}_{10}$ that includes the potential effect of proliferation, yielding $\mathrm{D}_{50}=55.7 \mathrm{~Gy} 10\left(\mathrm{EQD}_{2}=46 \mathrm{~Gy}\right)$ and $\gamma=1.04$.

Figure 4 shows the correlation between $\mathrm{BED}_{10}$ and local control among patients receiving RT only. As for overall survival, the data shows that higher $\mathrm{BED}_{10}$ correlate with improved local control. The dose response relationship yielded $\mathrm{D}_{50}=61.9 \mathrm{~Gy}_{10}\left(\mathrm{EQD}_{2}=52 \mathrm{~Gy}\right)$ and $\gamma=0.92$ for $\mathrm{BED}_{10}$ without proliferation and $\mathrm{D}_{50}=36.0 \mathrm{~Gy}_{10}\left(\mathrm{EQD}_{2}=30 \mathrm{~Gy}\right)$ and $\gamma=0.80$ for $\mathrm{BED}_{10}$ that accounts for proliferation.

\section{Late toxicity}

Late toxicity from bladder and rectum were recorded in 25 out of 171 patients (15\%), of which five patients showed complications from both organs. Bladder complications were found in 12 patients and 18 cases showed complications from rectum. Grade 2 and grade 3 complications were found in 23 and 2 patients, respectively.

Figure 5 shows the distribution of patients on the dose intervals from the point of view of the complications to the rectum and the bladder for the patients undergoing RT only. The $\mathrm{BED}_{3}$ has been calculated from the dose to the organ determined as described in the Materials and Methods section. The mean $\mathrm{BED}_{3}$ was $86 \mathrm{~Gy}_{3}\left(\mathrm{EQD}_{2}=51 \mathrm{~Gy}\right)$ for rectum and $76 \mathrm{~Gy}_{3}\left(\mathrm{EQD}_{2}=46 \mathrm{~Gy}\right)$ for bladder. Late rectal complications were recorded in $30.2 \%(13 / 43)$ for a mean $\mathrm{BED}_{3}$ of $83 \mathrm{~Gy}_{3}\left(\mathrm{EQD}_{2}=50 \mathrm{~Gy}\right)$ and bladder complications in $14 \%$ $(6 / 43)$ for a mean $\mathrm{BED}_{3}$ of $88 \mathrm{~Gy}_{3}\left(\mathrm{EQD}_{2}=53 \mathrm{~Gy}\right)$. No apparent dose correlation could be observed either for the rectum or the bladder.

\section{Discussion}

Radiation therapy is an important modality for the treatment of cervical cancers, alone or in combination with surgery. Several studies have investigated the outcome of RT 

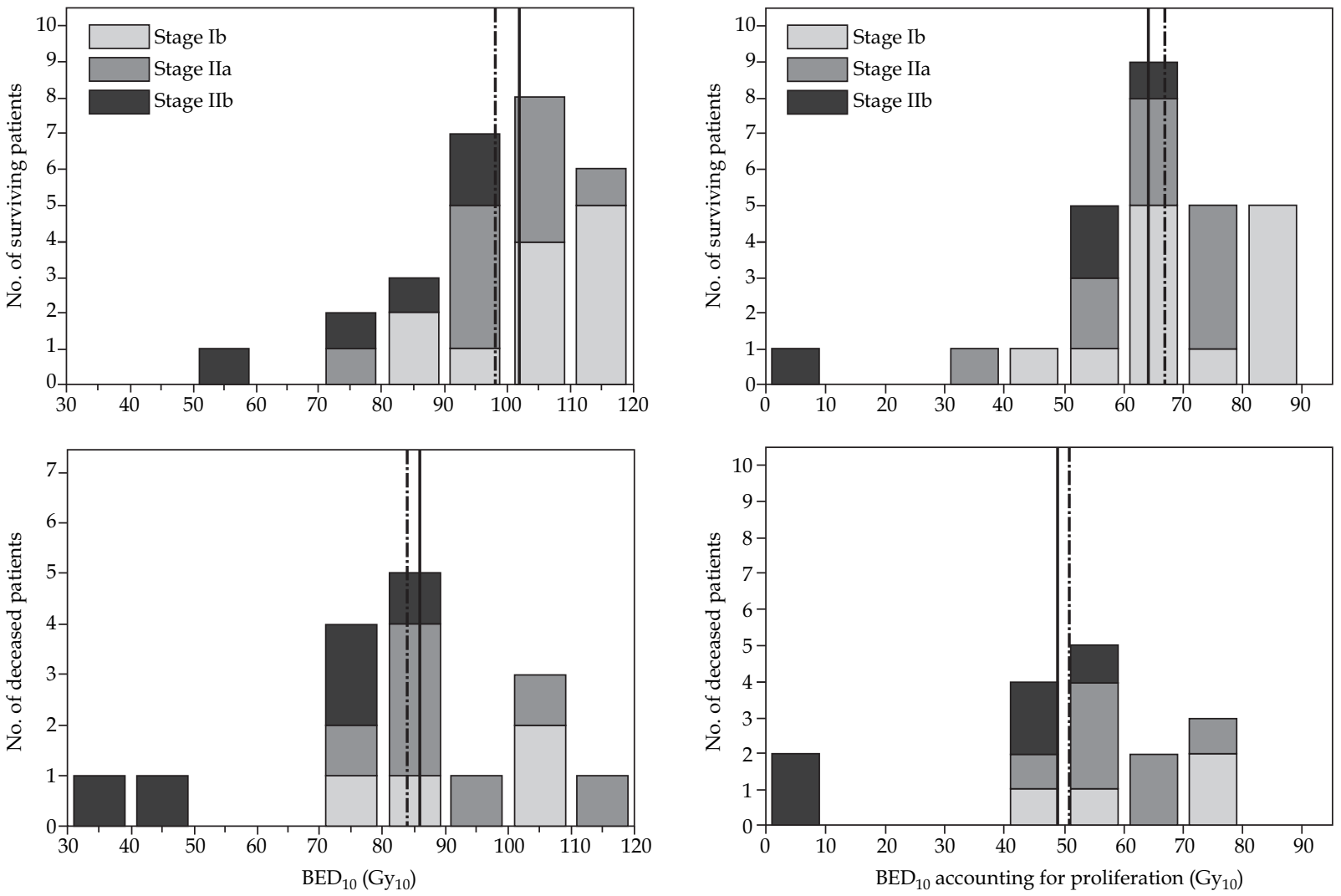

Fig. 1. $\mathrm{BED}_{10}$ and overall survival. Number of patients with stage $\mathrm{Ib}$, IIa and IIb cervical carcinoma as a function of $\mathrm{BED}_{10}$ to the tumour calculated with (right panels) and without proliferation (left panels)

Upper panels - no. of surviving patients (27)

Lower panel - no. of deceased patients (16)

Dashed lines indicate the mean $\mathrm{BED}_{10}$ and solid lines correspond to the median $\mathrm{BED}_{10}$

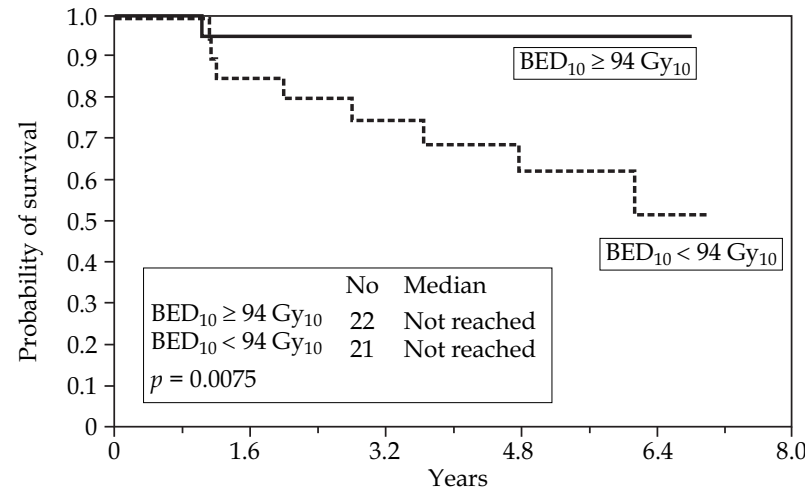

Fig. 2. Overall survival in patients treated with RT only, correlated to $\mathrm{BED}_{10}$ above median (number of patients $=21$ ) and below median (number of patients $=22$ ). Median $\mathrm{BED}_{10}=94 \mathrm{~Gy}_{10}$

in relation to $\mathrm{BED}$, but to our knowledge there are no reports on BED and outcome for patients treated with a combination of RT and surgery.

For treatment schedules including EBRT and BT it has been difficult to obtain a dose response relationship due to the diversity of combinations of treatment modalities and

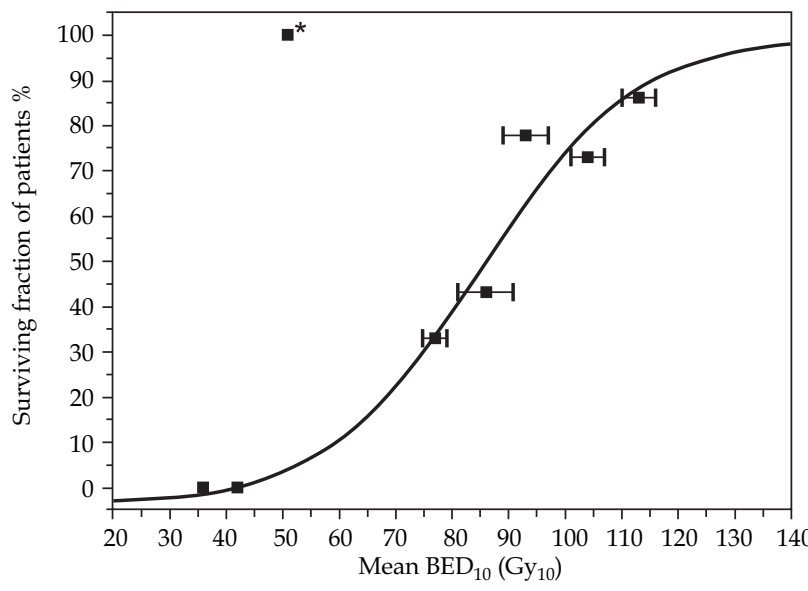

Fig. 3. Dose response curve illustrating the distribution of the surviving fraction of patients with respect to the mean $\mathrm{BED}_{10}$ for the 43 patients with stage Ib, IIa and IIb cervical carcinoma. The data point marked with * has been excluded from the fitting

the composition of the analyzed patient populations. In a large patterns of care study Lanciano et al. [20] reported no dose response relationship in the results from $1558 \mathrm{pa}$ - 

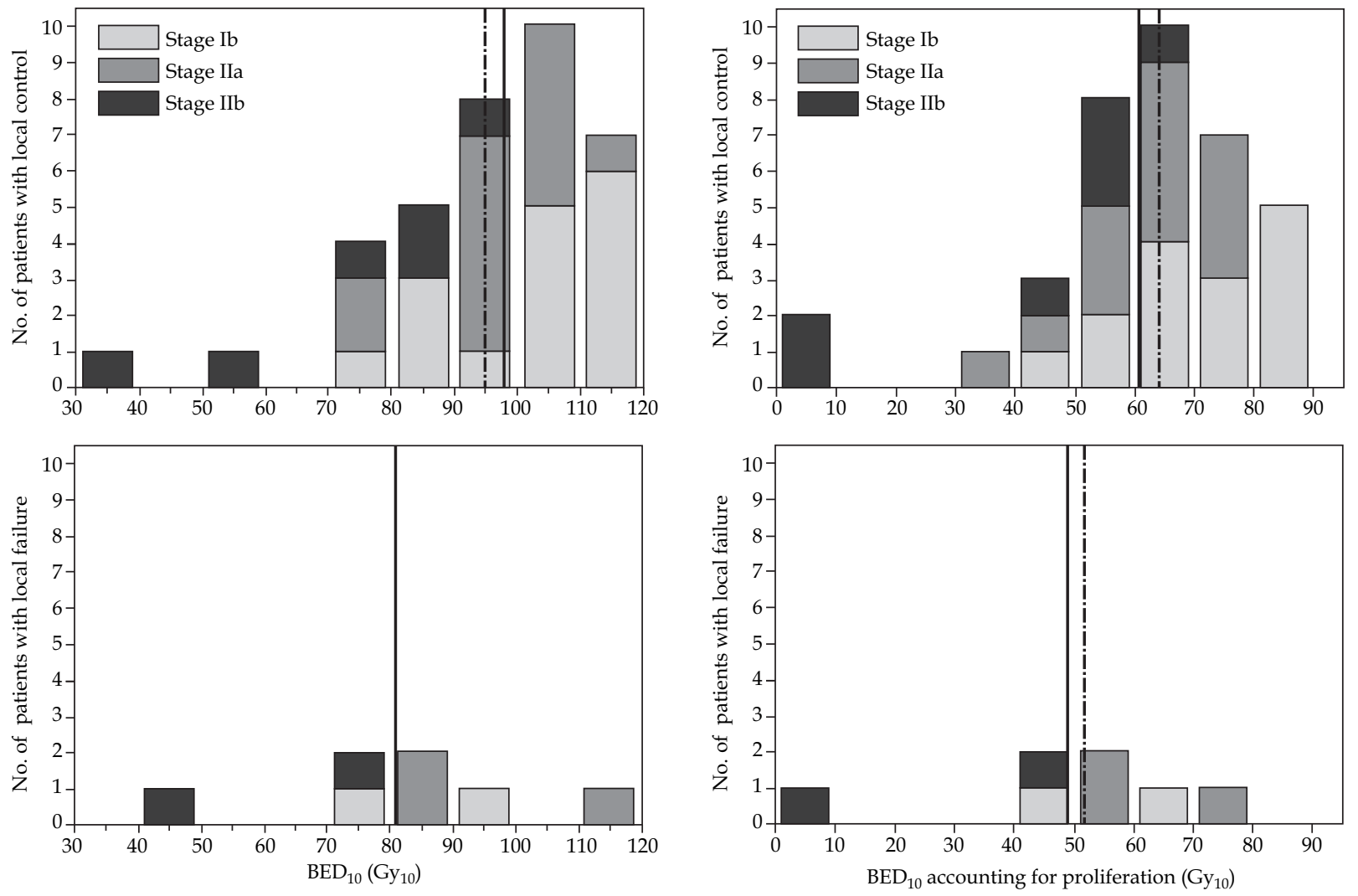

Fig. 4. $\mathrm{BED}_{10}$ and local control. Number of patients with stage $\mathrm{Ib}$, IIa and IIb cervical carcinoma as a function of $\mathrm{BED}_{10}$ to the tumour calculated with (right panels) and without proliferation (left panels)

Upper panel - no. of patients with local control (36)

Lower panel - no. of patients with local failure (7)

Dashed lines indicate the mean $\mathrm{BED}_{10}$ and solid lines correspond to the median $\mathrm{BED}_{10}$

tients treated with doses ranging from less than 75 Gy to more than 85 Gy in the clinical dose to Point A. Similarly, a review of 24 studies performed by Petereit and Pearcey [21] failed to find a correlation between $B D_{10}$ in Point $A$ and local control or survival in patients with cervical cancer stage I-III.

Evaluation of individual studies reporting various BEDs is very difficult due to the variation in the patient composition of the analyzed populations. In an analysis by Petereit et al. [22] comparing the outcome for stage I-III patients treated with HDR or LDR brachytherapy in combination with EBRT, $\mathrm{BED}_{10}$ varied in the range of $96-109 \mathrm{~Gy}_{10}$ and no doseresponse relationship for pelvic control or relapse-free survival and $\mathrm{BED}_{10}$ was found. In a later study, Sood et al. [11] reported a median $\mathrm{BED}_{10}$ of $87.3 \mathrm{~Gy}_{10}$ for patients with local control and $87.7 \mathrm{~Gy}_{10}$ for patients with local failure treated with RT alone. However, it should be noted, that Sood et al. [11] reported better local control for patients receiving treatments with $\mathrm{BED}_{10}$ above median than for patients with $\mathrm{BED}_{10}$ below the median.

Our results in terms of mean $\mathrm{BED}_{10}$ for the patients treated only with RT compare well with these reported studies. We found mean $\mathrm{BED}_{10}$ of $92 \mathrm{~Gy}_{10}$. Furthermore, we also found a positive correlation between the overall survival and BED in patients treated only with radiotherapy. The mean $\mathrm{BED}_{10}$ corresponding to a surviving fraction of $50 \%$ of the patients was $\mathrm{D}_{50}=85.2 \mathrm{~Gy}_{10}$ and $\gamma=1.62$. A similar analysis was performed with $\mathrm{BED}_{10}$ that includes the potential effect of proliferation, yielding $\mathrm{D}_{50}=55.7 \mathrm{~Gy}_{10}$ and $\gamma=1.04$. The latter analysis showed increased heterogeneity of the data, as supported by the lower $\gamma$, suggesting that proliferation may not be as important as recommended by the parameters used. Nevertheless, it has to be mentioned, that the observed trends were maintained even after the inclusion of a proliferation factor with generic parameters in the calculation of $\mathrm{BED}_{10}$. The size of the patient population available for this study does not however allow a more detailed analysis of the influence of proliferation. Though, investigating this aspect in the future is warranted.

Figure 4 shows the correlation between $\mathrm{BED}_{10}$ and local control in the investigated population. As for overall survival, data shows that higher $\mathrm{BED}_{10}$ correlate with improved local control. The dose response relationship yielded $\mathrm{D}_{50}=$ $61.9 \mathrm{~Gy}_{10}$ and $\gamma=0.92$ for $\mathrm{BED}_{10}$ without proliferation and $\mathrm{D}_{50}=36.0 \mathrm{~Gy}_{10}$ and $\gamma=0.80$ for $\mathrm{BED}_{10}$ that accounts for proliferation. As for overall survival, the analysis of the data that included proliferation showed increased heterogeneity, supporting the hypothesis that the proliferation in the investigated population might have other characteristics than predicted by the parameters used. 

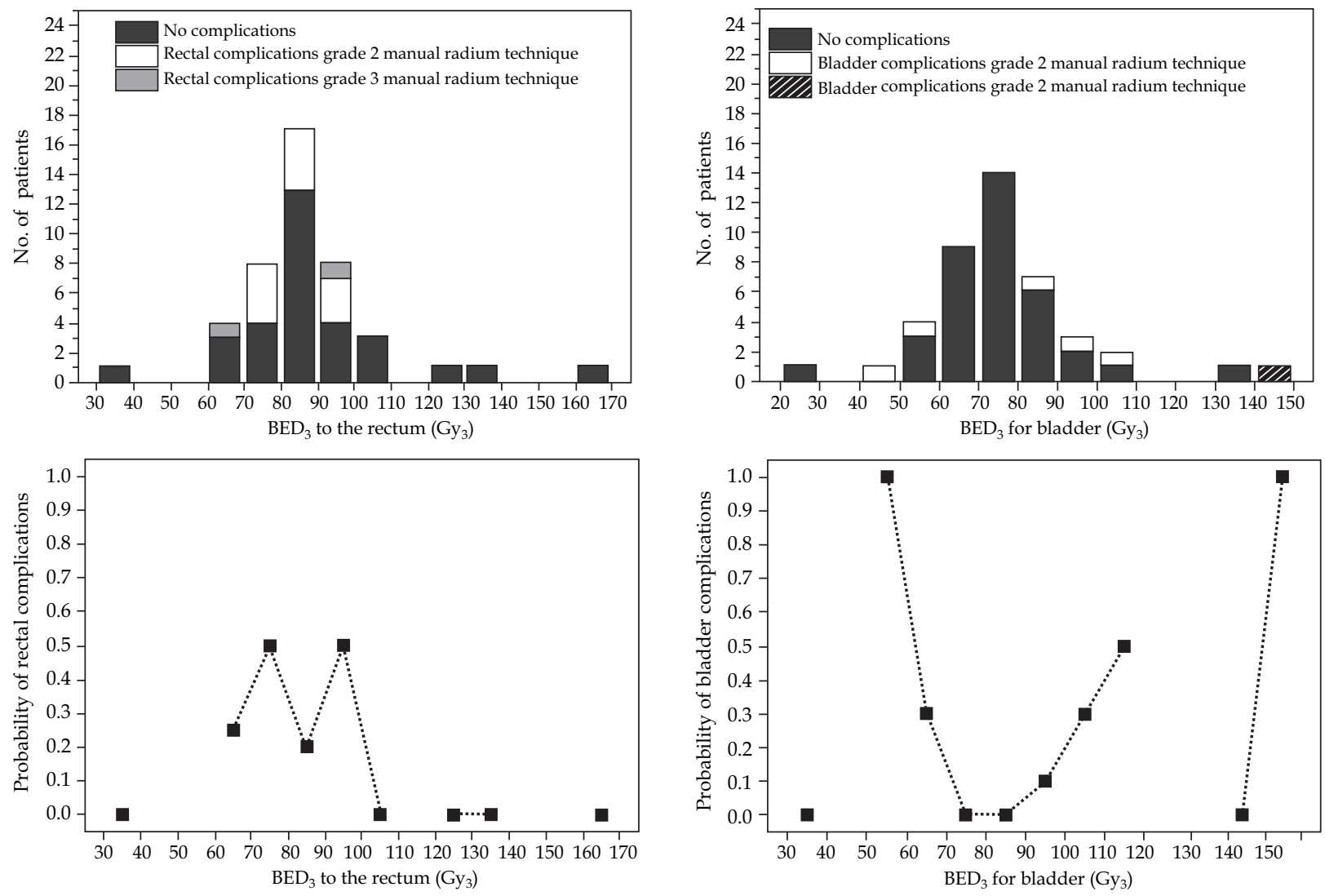

Fig. 5. Distribution of rectal and bladder complications with respect to $\mathrm{BED}_{3}$ for all 43 patients for stage $\mathrm{Ib}$, IIa and IIb cervical carcinoma expressed as number of patients (upper panels) and probability (lower panels)

The late rectal complication rate we have observed was $30 \%(13 / 43)$ and for the bladder complication rate was $14 \%$ $(6 / 43)$ calculated as the rate of complications for RT patients only. These compare well with the findings of Chen $e t$ al. [23] who reported $30 \%$ and $5 \%$ late complications from rectum and bladder, respectively. However, Lanciano et al. [20] reported a late complication rate of $9.5 \%$, but in that study only major complications were recorded. Sood et al. [11] in contrast reported only one late rectal complication among 26 patients treated with RT alone, but the definition of late complications it is not well described.

We found mean $\mathrm{BED}_{3}$ of $86 \mathrm{~Gy}_{3}$ for rectum and $76 \mathrm{~Gy}_{3}$ for bladder, with mean $\mathrm{BED}_{3}$ of $83 \mathrm{~Gy}_{3}$ and $88 \mathrm{~Gy}_{3}$ for patients with rectal and bladder complications, respectively. In a study of stage IB patients treated with RT by Lee $e t$ al. [10] mean rectal $\mathrm{BED}_{3}$ was $125.6 \mathrm{~Gy}_{3}$ for patients without rectal complications compared to $142.7 \mathrm{~Gy}_{3}$ for patients with late complications, and the rectal complications increased when mean $\mathrm{BED}_{3}$ was $\geq 131 \mathrm{~Gy}_{3}$. In our study we had only two patients with mean $\mathrm{BED}_{3} \geq 131 \mathrm{~Gy}_{3}$ and none of them were recorded with any late rectal complications.

In this study no correlation has been observed between the rate of complications and $\mathrm{BED}_{3}$ to the organs at risk. This is in agreement with the studies by Clark et al. [24] and Chen et al. [23] who reported $125 \mathrm{~Gy}_{3}$ and $110 \mathrm{~Gy}_{3}$, respectively threshold $\mathrm{BED}_{3}$ for the correlation between the dose and the rectal complications. Our median $\mathrm{BED}_{3}$ for the rectum of $85 \mathrm{~Gy}_{3}$ was lower than the reported threshold which could be one explanation to the lack of correlation. The low median $\mathrm{BED}_{3}$ in or study might lead to low level of complication probability, which would not totally agree to our results. This may be explained by the rather high age among patients treated with RT only. Another factor of importance could be the large fraction of patients treated with manual technique generally associated with higher dosimetric uncertainties. However, the results of other studies might also be subject to dosimetric uncertainties. This stresses the difficulties in comparing studies from different institutions, from different time periods or with different stage compositions of the patient populations.

It has to be mentioned that the predictions of complication rates based on correlations with the biological effective dose for the organs at risk are subject of discussion due to the intrinsic limitations of the BED concept, which does not take into account the volume effects and the dose heterogeneity within the organ. While for the tumors, these are not a critical issues since they are typical parallel structures and their treatment outcome would correlate with the minimum dose, for rectum or bladder the volume effect and the distribution of the dose within the organ might be of high importance. 


\section{Conclusions}

This study shows that the outcome of the treatment correlates with biological effective dose for patients treated only with radiation therapy, but not for patients treated with radiotherapy and surgery. The dose response parameters found based on $\mathrm{BED}_{10}$ calculations were $\mathrm{D}_{50}=85.2 \mathrm{~Gy}_{10}$ $\left(\mathrm{EQD}_{2}=71 \mathrm{~Gy}\right)$ and $\gamma=1.62$ for overall survival and $\mathrm{D}_{50}=$ $61.6 \mathrm{~Gy}_{10}\left(\mathrm{EQD}_{2}=52 \mathrm{~Gy}\right)$ and $\gamma=0.92$ for local control. No correlations were found between BED and late toxicity from bladder and rectum.

\section{Acknowledgements}

Mr. Ronny Westberg is greatly acknowledged for his professional assistance with the statistical calculations.

\section{References}

1. Perez CA, Grigsby PW, Camel HM et al. Irradiation alone or combined with surgery in stage IB, IIA, and IIB carcinoma of uterine cervix: update of a nonrandomized comparison. Int J Radiat Oncol Biol Phys 1995; 31: 703-716.

2. Landoni F, Maneo A, Colombo A et al. Randomised study of radical surgery versus radiotherapy for stage Ib-IIa cervical cancer. Lancet 1997; 350: 535-540.

3. Atlan D, Touboul E, Deniaud-Alexandre E et al. Operable Stages IB and II cervical carcinomas: a retrospective study comparing preoperative uterovaginal brachytherapy and postoperative radiotherapy. Int J Radiat Oncol Biol Phys 2002; 54: 780-793.

4. Jacinto AA, Castilho MS, Novaes PE et al. Preoperative external beam radiotherapy and reduced dose brachytherapy for carcinoma of the cervix: survival and pathological response. Radiat Oncol 2007; 2: 9.

5. Douglas BG, Fowler JF. Fractionation schedules and a quadratic dose-effect relationship. Br J Radiol 1975; 48: 502-504.

6. Barendsen GW. Dose fractionation, dose rate and iso-effect relationships for normal tissue responses. Int J Radiat Oncol Biol Phys 1982; 8: 1981-1997.

7. Fowler JF. The linear-quadratic formula and progress in fractionated radiotherapy. Br J Radiol 1989; 62: 679-694.

8. Gasinska A, Fowler JF, Lind BK et al. Influence of overall treatment time and radiobiological parameters on biologically effective doses in cervical cancer patients treated with radiation therapy alone. Acta Oncol 2004; 43: 657-666.

9. Leborgne F, Fowler JF, Leborgne JH et al. Biologically effective doses in medium dose rate brachytherapy of cancer of the cervix. Radiat Oncol Investig 1997; 5: 289-299.

10. Lee SW, Suh CO, Chung EJ et al. Dose optimization of fractionated external radiation and high-dose-rate intracavitary brachytherapy for FIGO stage IB uterine cervical carcinoma. Int J Radiat Oncol Biol Phys 2002; 52: 1338-1344.

11. Sood B, Garg M, Avadhani J et al. Predictive value of linearquadratic model in the treatment of cervical cancer using highdose-rate brachytherapy. Int J Radiat Oncol Biol Phys 2002; 54: 1377-1387.

12. Bianchi C, Botta F, Conte L et al. Biological effective dose evaluation in gynaecological brachytherapy: LDR and HDR treatments, dependence on radiobiological parameters, and treatment optimisation. Radiol Med 2008; 113: 1068-1078.

13. Haie-Meder C, Chargari C, Rey A et al. DVH parameters and outcome for patients with early-stage cervical cancer treated with preoperative MRI-based low dose rate brachytherapy followed by surgery. Radiother Oncol 2009; 93: 316-321.
14. Chassagne D, Sismondi P, Horiot JC et al. A glossary for reporting complications of treatment in gynecological cancers. Radiother Oncol 1993; 26: 195-202.

15. International Commission on Radiation Units and Measurements. ICRU report no. 38: Dose and volume specification for reporting intracavitary therapy in gynecology. 1985.

16. Beskow C, Agren-Cronqvist AK, Granath F et al. Pathologic complete remission after preoperative intracavitary radiotherapy of cervical cancer stage Ib and IIa is a strong prognostic factor for long-term survival: analysis of the Radiumhemmet data 1989-1991. Int J Gynecol Cancer 2002; 12: 158-170.

17. Withers HR, Maciejewski B, Taylor JM et al. Accelerated repopulation in head and neck cancer. Front Radiat Ther Oncol 1988; 22: 105-110.

18. Thames HD, Bentzen SM, Turesson I et al. Time-dose factors in radiotherapy: a review of the human data. Radiother Oncol 1990; 19: 219-235.

19. Pötter R, Haie-Meder C, Van Limbergen E et al. Recommendations from gynaecological (GYN) GEC ESTRO working group (II): concepts and terms in 3D image-based treatment planning in cervix cancer brachytherapy-3D dose volume parameters and aspects of 3D image-based anatomy, radiation physics, radiobiology. Radiother Oncol 2006; 78: 67-77.

20. Lanciano RM, Won M, Coia LR et al. Pretreatment and treatment factors associated with improved outcome in squamous cell carcinoma of the uterine cervix: a final report of the 1973 and 1978 patterns of care studies. Int J Radiat Oncol Biol Phys 1991; 20: 667-676.

21. Petereit DG, Pearcey R. Literature analysis of high dose rate brachytherapy fractionation schedules in the treatment of cervical cancer: is there an optimal fractionation schedule? Int J Radiat Oncol Biol Phys 1999; 43: 359-366.

22. Petereit DG, Sarkaria JN, Potter DM et al. High-dose-rate versus low-dose-rate brachytherapy in the treatment of cervical cancer: analysis of tumor recurrence - the University of Wisconsin experience. Int J Radiat Oncol Biol Phys 1999; 45: 1267 1274.

23. Chen SW, Liang JA, Yang SN et al. The prediction of late rectal complications following the treatment of uterine cervical cancer by high-dose-rate brachytherapy. Int J Radiat Oncol Biol Phys 2000; 47: 955-961.

24. Clark BG, Souhami L, Roman TN et al. The prediction of late rectal complications in patients treated with high dose-rate brachytherapy for carcinoma of the cervix. Int J Radiat Oncol Biol Phys 1997; 38: 989-993. 